\title{
TEORÍA Y PRÁCTICA DE LA RELACIÓN DIALÉCTICA ENTRE DESARROLLO Y MIGRACIÓN
}

\author{
RAÚL DELGADO WISE* \\ HUMBERTO MÁRQUEZ COVARRUBIAS**
}

RESUMEN: En este artículo analizamos los elementos teóricos y prácticos que subyacen en la relación entre la problemática del desarrollo y la migración internacional, a partir de la perspectiva de los países subdesarrollados exportadores de fuerza de trabajo y desde de la economía política del desarrollo. Esta visión se postula como una alternativa teórica frente a la formulación unidireccional migración-desarrollo refrendada por los principales organismos internacionales, basada en la idea de que los migrantes y sus recursos constituyen la agencia y el instrumento del desarrollo, respectivamente. Nuestro propósito es evidenciar el papel conferido a los migrantes en los procesos de acumulación e integración regional comandados por los países desarrollados receptores de fuerza de trabajo migrante y, en contrapartida, desentrañar su contribución al sostenimiento de la precaria estabilidad socioeconómica en sus países de origen. Como referente empírico, exploramos el caso de México, primer exportador mundial de migrantes y receptor de remesas.

PALABRAS CLAVE: Migración y desarrollo; economía política del desarrollo; migración forzada; transformación social; migración México-Estados Unidos.

ABSTRACT: In this paper we analyze the theoretical and practical aspects underlying the relationship between development and international migration taking into consideration the perspective of the labor-sending underdeveloped countries from a political economy of development approach. Against the unidirectional formulation of the migration-development nexus adopted by the major international organizations, this perspective offers a theoretical alternative based on the assumption that migrants and their resources, correspondingly represent the agency and instrument for development. Our purpose is both to disentangle the role assigned to migrants in the accumulation and regional integration processes leaded by the labor-receiving developed countries, and to unravel the migrant's

\footnotetext{
* Secretario ejecutivo de la Red Internacional de Migración y Desarrollo y director del Doctorado en Estudios del Desarrollo de la Universidad Autónoma de Zacatecas. Correo electrónico: rdwis e@estudiosdeldesarrollo.net.

** Profesor-investigador del Doctorado en Estudios del Desarrollo de la Universidad Autónoma de Zacatecas. Correo electrónico: hmarquez@estudiosdeldesarrollo.net.
} 
contribution in supporting the precarious socioeconomic stability of their countries of origin. We take as an empirical referent for our analysis the case of Mexico, the world's leading migrant-exporter and remittance-receiving country.

KEY WORDS: Migration and development; political economy of development; compulsory migration; social transformation; Mexico-US migration.

\section{INTRODUCCIÓN}

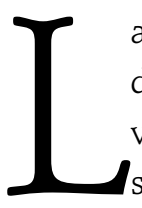

a mayor parte de los estudios que abordan la relación entre migración y desarrollo giran en torno al primer factor, como si la migración fuese una variable independiente y las posibilidades o no de desarrollo estuviesen supeditadas a los recursos e iniciativas de los migrantes. No obstante, dada la complejidad analítica que reviste esa relación, se advierte la necesidad de emprender estudios que se salgan de los linderos de ese esquema analítico, que tiene como punto de partida el fenómeno migratorio (véase figura 1), para colocarse justamente del otro lado de la ecuación, es decir, de los macroprocesos de desarrollo. Esta nueva perspectiva analítica considera a la migración como un aspecto de la problemática del desarrollo y visualiza al desarrollo como un campo analítico cuyas dinámicas estructurales y prácticas estratégicas tienen como escenario los planos global, regional, nacional y local. Asimismo, ante el predominio de la visión teórica y política de los países desarrollados receptores de inmigrantes, es necesario trastocar esa hegemonía e incorporar la visión de los países subdesarrollados exportadores de migrantes. Y ante el predominio de perspectivas de corte nacionalista o localista, conviene impulsar el análisis comparativo de corte internacional que rescate las experiencias en materia tanto de desarrollo y migración, como de la relación entre ambos.

FIGURA 1

Visión unidireccional del nexo migración y desarrollo

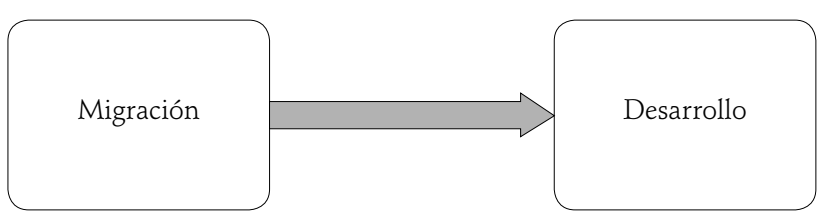

Desde nuestra óptica, es preciso situar el problema de la migración internacional en el ámbito de los estudios del desarrollo y, en consecuencia, asumir como premisa explicativa la problemática del desarrollo sobre la dinámica migratoria (véase figura 2). Para ello es necesario también generar objetos teóricos desde una perspectiva interdisciplinaria, es decir, conceptos y proposiciones sobre el contexto, agentes y procesos esenciales que operan en un ámbito multiespacial. Adicionalmente, es preciso problematizar y contextualizar la noción de desarrollo, para rebasar los marcos normativos que se constriñen a enunciar en términos abstrac- 
tos el mejoramiento de las condiciones socioeconómicas de la población, sin contemplar la necesidad de generar cambios estructurales e institucionales. Más aún, el problema del desarrollo en condiciones de alta migración agrega otros desafíos, tales como las asimetrías entre países, la reconfiguración de las cadenas productivas y la concomitante reestructuración y precarización de los mercados laborales, las desigualdades sociales en el horizonte transterritorial y, más específicamente, el deterioro de las bases materiales y subjetivas de arraigo de la población en los países de origen, aunado a la problemática de integración a las sociedades receptoras y el mantenimiento de vínculos transnacionales.

FIGURA 2

Una visión alternativa del nexo migración y desarrollo

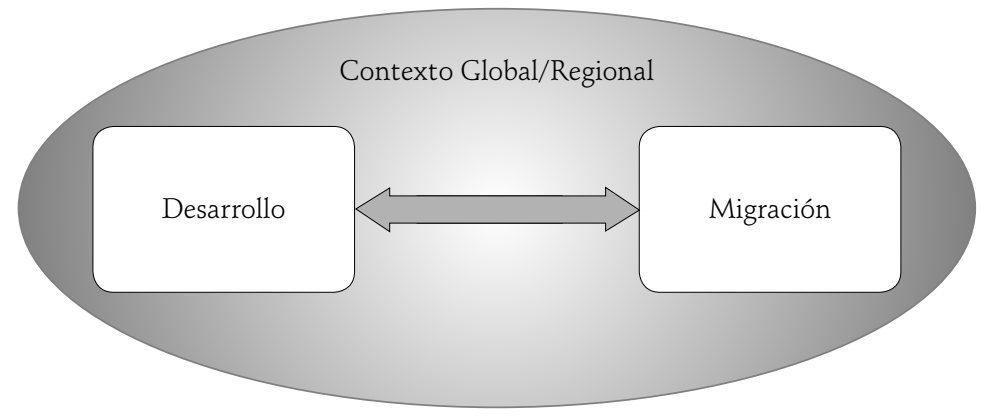

A nivel teórico y conceptual, el desafío inicial para la investigación de la relación entre migración y desarrollo deviene del hecho de que no se ha teorizado con propiedad el problema y que previamente no se ha realizado una operación que permita la adecuada incorporación del tema migratorio en los estudios del desarro1lo. Sin desconocer los aportes de la amplia constelación de estudios, autores y temas de debate, consideramos que para construir una visión integral de la relación entre desarrollo y migración, es necesario incorporar, en un marco analítico más comprehensivo, una perspectiva del contexto de integración socioeconómica regional y de la problemática del desarrollo en el país emisor de migrantes para poder establecer a nivel teórico y práctico la específica conexión entre migración y desarrollo.

Esta reconstrucción crítica del campo de estudios de migración y desarrollo significa, también, sobreponerse a la visión parcial de los países desarrollados importadores de migrantes basada en principios como la gestión de la migración, la agenda de seguridad, el codesarrollo y la criminalización de los inmigrantes. Por tanto, es imprescindible incorporar la visión de los países subdesarrollados exportadores de migrantes, a partir de una comprensión del contexto de desarrollo del capitalismo contemporáneo y el tipo de relaciones asimétricas entre países expulsores y receptores de migrantes. Cabe señalar que el esfuerzo de teorizar desde la perspectiva de los países subdesarrollados, que implica una visión comprehensiva del fenómeno, no es una tarea nueva. Desde la década de los cincuenta y hasta los 
setenta, las teorías del estructuralismo de la CePAL y las teorías de la dependencia -estas últimas generadas, aunque con algunas variantes, bajo el paraguas de la economía política marxista- aportaron un sólido basamento para avanzar en esta dirección (Marini, 1973; Dos Santos, 1974; Furtado, 1969; Cardoso y Faletto, 1969; Frank, 1974; Bambirra, 1978). Se trata de concepciones que trascienden al nacionalismo metodológico con mucha antelación a la emergencia del enfoque transnacionalista que reivindica como su acto fundacional esa premisa. En términos generales, no deja de ser sintomático el grado de desconocimiento u omisión que teóricos y analistas de los países desarrollados hacen de las aportaciones de los teóricos latinoamericanos y del resto del mundo subdesarrollado.

Partiendo de estas grandes premisas, el presente trabajo se divide en dos apartados y unas conclusiones generales. En el primero se delinea nuestra perspectiva teórica de cómo abordar el vínculo entre desarrollo y migración bajo un esquema analítico comprehensivo desde la visión de los países exportadores de fuerza de trabajo. En el segundo apartado se muestra la capacidad interpretativa del enfoque propuesto tomando como referente el caso de la migración México-Estados Unidos en el contexto actual de integración asimétrica de América del Norte.

\section{LA ECONOMÍA POLÍTICA DEL DESARROLLO Y LA MIGRACIÓN: HACIA UN NUEVO ENFOQUE ANALÍTICO}

Heredera de la perspectiva estructuralista latinoamericana y particularmente de las teorías de la dependencia, la economía política del desarrollo provee de una caja de herramientas sine qua non para el abordaje de nuestro objeto de estudio, al considerar:

1. el amplio espectro de relaciones que entraña la dinámica norte-sur o desarrollosubdesarrollo, sin perder de vista los niveles de diferenciación existentes al interior de cada uno de los polos de la relación;

2. la interacción entre diferentes niveles espaciales (local, nacional, regional y global) y dimensiones sociales (económica, política, cultural, ambiental);

3. una visión transdisciplinaria que concita la unción crítica de varias disciplinas en la reconstrucción de la realidad y la reflexión teórica, contrariamente al estereotipo del «economicismo» $y$ «estructuralismo» con el que se ha querido encasillar;

4. una noción de desarrollo que rebasa las concepciones estrechamente normativas y descontextualizadas, al considerar la necesidad de la transformación social, que implica un cambio en el orden estructural, estratégico e institucional, en aras de generar mejores condiciones de vida para el conjunto de la población. Este proceso debe operar bajo la directriz de un proyecto transformador encausado por una amalgama de actores, movimientos, agentes e instituciones sociales que operan en distintos planos y niveles. 
Bajo el prisma de la economía política del desarrollo y en el contexto actual de la globalización neoliberal, la relación entre la migración internacional y el desarrollo adquiere una interacción dialéctica que se despliega en varios planos analíticos que superan la visión dominante y unidireccional de migración-desarrollo. Con referencia específica a la migración sur-norte o de los países subdesarrollados a los desarrollados, podemos destacar los siguientes niveles del proceso dialéctico de la relación entre desarrollo y migración:

1. El subdesarrollo produce migración forzada ${ }^{1}$ hacia los países desarrollados. En el contexto de la globalización neoliberal, los países desarrollados despliegan una estrategia imperialista de reestructuración que a la vez que internacionaliza los procesos productivos, comerciales y financieros, se apropian de recursos naturales, excedentes económicos y fuerza de trabajo barata de los países subdesarrollados. El tipo de relaciones que tensan los países centrales con los países periféricos y poscoloniales propicia la profundización de las condiciones de subdesarrollo de éstos últimos. En ese trance, los países subdesarrollados producen reservas de población redundante o sobrepoblación que no encuentra condiciones laborales que les permita la reproducción personal y familiar, debido a la existencia de procesos de acumulación disminuidos derivados de las relaciones asimétricas que establecen con los países desarrollados (intercambio desigual que se traduce en distintas formas de transferencia de excedentes). Estas condiciones de insustentabilidad social precipitan la migración forzada, entendida como la movilidad poblacional derivada de la cancelación de condiciones de vida y trabajo dignos y suficientemente remunerados o detonados por conflictos políticos y sociales que ponen en peligro la vida de la población. El exacerbamiento de la migración forzada genera, para los países de origen, una inapreciable pérdida poblacional, que en algunos casos se traduce en despoblamiento relativo, incluso absoluto. La sangría de fuerza de trabajo calificada y no calificada está asociada también al abandono de actividades productivas y a la pérdida de riqueza potencial.

2. Los migrantes contribuyen al desarrollo del país receptor. Los países centrales demandan ingentes cantidades de fuerza de trabajo barata calificada y no calificada, incluso indocumentada para una mayor vulnerabilidad y desvalorización de esta mercancía humana. Esta demanda obedece, en primer término, a la capacidad ampliada de acumulación derivada de la inyección de recursos que perciben de la transferencia de recursos y excedentes de los países subdesarrollados y, en segundo término, en virtud de la existencia de procesos de transición demográfica y consecuente envejecimiento poblacional. En esas condiciones, los inmigrantes contribuyen al abaratamiento general de la fuerza de trabajo debido a que laboran en sectores productivos demandantes de trabajo intensivo, generadores de bienes salarios, en proceso de rescate o en sustitución de sectores laborales que perciben mayores salarios y detentan mejores prestaciones. La fuerza de trabajo inmigrante calificada, si bien se concibe como un sector de élite laboral, en términos relativos tam-

${ }^{1}$ La noción de migración forzada que aplicamos amplía aquella que tradicionalmente se utiliza en los estudios sobre refugiados y asilados, incorporando, como se plantea en el texto de este inciso, la dimensión económica. 
bién es trabajo barato porque percibe un ingreso menor a sus pares con igual formación y capacidades pero con ciudadanía acreditada en el país receptor. Tanto en el caso de inmigrantes calificados como no calificados, el país receptor obtiene una gran ventaja puesto que no ha aportado prácticamente ningún recurso al fondo social destinado a su formación en el país de origen, por lo cual la migración también constituye una transferencia por partida doble: fuerza de trabajo barata y costos de formación. El aporte de los migrantes no sólo configura una ventaja comparativa estática derivada del abaratamiento de los costos de producción, sino que contribuye también al establecimiento de ventajas comparativas dinámicas derivadas de su colaboración en la aceleración de los procesos de innovación. En conjunto, los inmigrantes laborales y sus familiares contribuye al fortalecimiento del mercado interno del país receptor a través del consumo, incluso el llamado mercado nostálgico en el fondo constituye la organización de una demanda erigida por un sector de consumidores en constante crecimiento que fortifica la actividad económica interna; por otra parte, también abonan mediante el pago de impuestos a la formación del fondo fiscal, mismo que sin embargo no retribuyen en una proporción equiparable a otros sectores poblacionales con la prestación de servicios y bienes públicos, lo cual denota un criterio de exclusión social. Además, el aporte de los migrantes se aviene como una tabla de salvación para solventar el agudo problema de las pensiones que se presenta como resultado de un proceso masivo de jubilación de la llamada generación del baby boom. Estas contribuciones, que compensan algunos de los efectos del desmantelamiento del Estado de bienestar que acusan las economías desarrolladas, no constituyen obviamente una solución perdurable. ${ }^{2}$

3. Los migrantes contribuyen al sostenimiento de la precaria estabilidad socioeconómica del país de origen. Una fracción del salario devengado por los inmigrantes se destina, bajo la modalidad de remesa salarial, ${ }^{3}$ a la subsistencia de los miembros de la familia que radican en los lugares de origen. En menor medida, las remesas se destinan a financiar pequeños establecimientos inmersos en la economía de subsistencia. Las organizaciones de migrantes recaban recursos, la remesa participativa, que se canalizan a la realización de obra pública y proyectos sociales en sus lugares de origen. En casos como México esta práctica se ha institucionalizado en el Programa Tres por Uno, que ha sido replicado en otros países. En menor proporción, los migrantes ahorradores o empresarios canalizan sus recursos, remesas productivas, para financiar microproyectos en sus lugares de origen. Sin embargo, el componente más importante de las remesas son las salariales, dirigidas al consumo familiar, por lo que difícilmente los recursos enviados por los migrantes se inscriben en procesos de desarrollo abocados a la transformación social. En el entorno macroeconómico, la sumatoria de las remesas rinde buenos frutos a los gobiernos neoliberales, que sin preocuparse de generar alternativas de desarrollo, se sirven

${ }^{2}$ Es pertinente hacer notar que, con el avance y desarrollo de la dinámica migratoria, se configura un complejo espacio social transnacional que atraviesa las sociedades de origen y destino y representa un campo dinámico para la actividad económica, el cual por lo general es objeto de ganancias para las grandes corporaciones de los países desarrollados (Guarnizo, 2003).

${ }^{3}$ La tipología de remesas que se emplea en este inciso se encuentra en Márquez Covarrubias (2006). 
de las remesas como una fuente de divisas que coadyuva al sostenimiento de la endeble «estabilidad macroeconómica», incluso se llega al punto de emplear el rubro de remesas como garantía para la contratación de deuda externa. Ante la ausencia de un proyecto de desarrollo, se ha llegado al cinismo de señalar a los migrantes como los «héroes del desarrollo», lo cual significa realmente que se les achaca una responsabilidad en la promoción del desarrollo, en un escenario donde el Estado, bajo la consigna conservadora del Estado mínimo, se retira de las tareas propias de la gestión del desarrollo. Bajo el estratagema de la mano invisible del mercado que postula el fundamentalismo neoliberal, se adolece de la falta de un proyecto de desarrollo que involucre en otra tónica a los migrantes y otros sectores sociales y se anteponga la necesidad de impulsar procesos de transformación social. En el fondo, se mantiene la función de estos países como reservas laborales al tiempo en que se obstruyen deliberadamente las posibles alternativas en beneficio de los intereses de una cada vez más reducida élite asociada a los intereses de las muy exclusivas élites de los países desarrollados comandados preponderantemente por el gran capital estadounidense.

4. La promoción del desarrollo como transformación social puede contener la migración forzada. En contraposición a la visión ideológica de la globalización y de la mercadocracia neoliberal que postulan la idea de su inevitabilidad, es imprescindible refrendar en términos teóricos y prácticos la factibilidad de impulsar cursos alternativos para detonar procesos de desarrollo en distintos niveles. En principio, es menester redefinir los términos de las relaciones asimétricas y de franca dominación que imponen los países desarrollados sobre el mundo subdesarrollado al amparo de principios vueltos fetiches como la democracia, la libertad y el libre comercio. Esto significa poner a la luz las prácticas imperialistas que sumen en el subdesarrollo a vastas regiones del mundo y generan océanos de desigualdad, marginación, pobreza, exclusión social y migración galopante. En este sentido, los gobiernos de estirpe neoliberal de los países de origen aducen que la migración es un proceso inevitable, y se conforman con hacer la sumatoria ascendente de la captación de remesas, incluso en tono triunfalista, en una lógica que parece invocar al dicho de «estirar la cuerda hasta que se rompa». Empero, un verdadero proyecto de transformación social que haga participe a los sectores sociales migrantes y no migrantes no sólo está llamado a contener la caudalosa migración forzada sino también a revertir los procesos de degradación social propios del subdesarrollo que ponen en predicamento incluso la existencia humana (Harvey, 2007; Bello, 2006).

Partiendo de las consideraciones anteriores, el enfoque de la economía política del desarrollo considera que la migración internacional deviene de los problemas del desarrollo y que el fenómeno migratorio no puede estudiarse en sí mismo para dilucidar sus causas y efectos más profundos. Para abordar el estudio de la cuestión migratoria en su doble interrelación con la problemática del desarrollo -es decir como efecto y como causa-, y más aún para diseccionar los distintos momentos de la relación dialéctica entre desarrollo y migración, resulta fundamental considerar dos dimensiones analíticas fundamentales: prácticas estratégicas y dinámicas estructurales (véase figura 3). 
FIGURA 3

Dimensiones analíticas de la economía política del desarrollo

Dimensión Estratégica
$\begin{gathered}\text { Sujetos y } \\ \text { agentes sociales }\end{gathered}$$\left\{\begin{array}{l}\text { Dimensión Estructural } \\ \text { Contexto global } \\ \text { Integración regional } \\ \text { Entorno nacional } \\ \text { Niveles intranacionales }\end{array}\right.$

\section{Prácticas estratégicas}

Se refiere a la confrontación de proyectos portadores de intereses divergentes que subyacen en el entramado estructural del capitalismo contemporáneo y en los problemas del desarrollo que le son inherentes. Se pueden destacar dos grandes proyectos: 1) el hegemónico, que promueven las grandes corporaciones transnacionales junto con los gobiernos de los países desarrollados comandados por Estados Unidos -en alianza con algunas élites de los países subdesarrollados-, y bajo el paraguas de algunos organismos internacionales. No obstante, ante la pérdida de legitimidad del proyecto que entraña la globalización neoliberal, hoy en día, más que hablar de hegemonía, conviene emplear el término de dominación, porque el proyecto no se impone por el consenso, sino mediante la coacción militar y la imposición financista del Consenso y Posconsenso de Washington, y 2) el alternativo, referido a la acción sociopolítica que aglutina a movimientos y clases sociales, agentes y sujetos colectivos, de conformidad a un proyecto político concientemente diseñado en aras de transformar las dinámicas estructurales y el entorno político e institucional que obstaculiza la promoción de alternativas de desarrollo en los ámbitos global, regional, nacional y local.

Los principales agentes que comandan los procesos de desarrollo y migración son la corporaciones transnacionales, los gobiernos de los países desarrollados importadores de migrantes y los organismos internacionales, además del capital nacional asociado, cuyo ámbito de acción alcanza las dimensiones de la globalización neoliberal, la regionalización y el desarrollo nacional, incluso el desarrollo local. Los gobiernos de los países subdesarrollados exportadores de migrantes carecen, en el mayor de los casos, de un proyecto de nación y están subordinados a los intereses de los agentes clave. Su cobertura se limita a incidir, en algún grado, en las dimensiones del desarrollo nacional y local. No obstante, el dinamismo y madurez relativa de algunas diásporas, como la mexicana, da lugar a la emergencia de nuevos sujetos sociales, particularmente las organizaciones de migrantes, muchas de las cuales incursionan en procesos de desarrollo en sus lugares de origen, su margen de actuación es transnacional, entre los países de origen y desti- 
no, aunque no con la misma intensidad, pero destaca su participación en incipientes procesos de desarrollo local. Los migrantes, organizados o no, mantienen vínculos permanentes y dinámicos con sus lugares de origen y participan, sobre todo los organizados, en procesos locales situados en los espacios marginales que produce el nuevo orden mundial. Así, pues, los sujetos de la migración tienen su propio ámbito de acción, como se describió, algunos atraviesan todos o varios de los niveles, en tanto que otros se circunscriben a su propio nicho de acción sin influir mayormente en el desempeño e intereses de los otros actores.

\section{Dinámicas estructurales}

Se refiere a la forma desigual y asimétrica en que se articula el capitalismo contemporáneo en distintos planos y niveles. Tienen cabida aquí los elementos que dan cuerpo a las esferas dominantes que rigen las finanzas, el comercio, la producción y los mercados laborales. Asimismo, se articulan otros ámbitos como la innovación tecnológica en tanto elemento estratégico en el control de las esferas antes referidas, junto al uso y destino de los recursos naturales y sus impactos ambientales. Estas demarcaciones estructurales moldean la forma en que se establecen las relaciones entre i) los países desarrollados, ii) los países desarrollados y subdesarrollados, y iii) los países subdesarrollados; a su vez, dichas demarcaciones determinan los campos en que se desarrollan las relaciones entre sectores, grupos, movimientos y clases sociales. Todo esto tiene expresiones distintas y particulares en los niveles global, regional, nacional y local.

1) Contexto global. Los países desarrollados se encuentran inmersos en un amplio y complejo proceso de reestructuración del capitalismo a escala mundial. Aunado a estrategias como la innovación en tecnologías de la información y comunicación, la terciarización de las economías y la internacionalización de las finanzas; a nivel global se aplican dos estrategias cruciales: la internacionalización de la producción y la transnacionalización, diferenciación y precarización de los mercados laborales. En ese sentido, el capitalismo contemporáneo ha organizado un nuevo orden mundial cuyo entramado, la globalización neoliberal, reproduce las asimetrías socioeconómicas entre países desarrollados y subdesarrollados a una escala inusitada, además de que profundiza las desigualdades sociales, la pobreza y la marginación al interior de los países subdesarrollados exportadores de migrantes. En los países importadores y exportadores de migrantes, el Estado de bienestar, o la modalidad que se le asemeja, está siendo desmantelado, al tiempo en que los mercados laborales se flexibilizan y precarizan al extremo y el medio ambiente se deteriora irreversiblemente. En ese contexto, el desarrollo, aunque presente en el discurso de los organismos internacionales y en la agenda de los Estados, ha sido abandonado y sus objetivos se han convertido en letra muerta. 
Empero, el desarrollo, más que nunca, representan una asignatura pendiente y uno de los grandes desafíos de la humanidad en la actualidad.

2) Integración regional. Los países desarrollados configuran bloques económicos regionales para, entre otros fines, expandir territorialmente los linderos de su mercado interno, ampliar su plataforma productiva y garantizar sus abastos de fuerza de trabajo barata, recursos naturales y excedente económico. Lo anterior se puede ilustrar con el bloque de América del Norte y la Unión Europea. En ese ámbito, se configuran mercados laborales transnacionales que asignan un papel clave a la fuerza de trabajo barata en la reestructuración productiva, que tiene lugar luego de la crisis experimentada por el capitalismo mundial en los setenta, como parte de una estrategia competitiva para abaratar los costos de producción. Para los países subdesarrollados que participan directa o indirectamente en un esquema de integración regional comandado por las grandes potencias capitalistas, la exportación de fuerza de trabajo barata acentúa las relaciones de dependencia que mantiene con los países centrales. En la configuración del bloque regional descansa la forma particular en que se articulan las estrategias de transnacionalización de los mercados financieros, la reestructuración productiva y la internacionalización de la producción, entre otros procesos; pero también pone en marcha una estrategia permanente de abaratamiento y precarización de la fuerza de trabajo, como arma competitiva contra los otros bloques regionales a fin de aceitar la reestructuración productiva e incrementar los márgenes de ganancia. La economía del trabajo barato llevada a extremos hasta hace pocas décadas insospechados es, hoy por hoy, uno de los principios básicos mediante los cuales opera el sistema capitalista global y el modo como el trabajo inmigrante se introduce en los países centrales. En este contradictorio contexto, la migración internacional, particularmente la de carácter laboral, crece exponencialmente al punto en que es ya una pieza clave del nuevo engranaje mundial, en virtud de la contribución de los migrantes en distintos grados y niveles al desarrollo económico, social y cultural de los países importadores y exportadores de migrantes. Empero, en muchos países receptores, los migrantes son sometidos a ingentes procesos de explotación laboral, expuestos a un clima de xenofobia y racismo y responsabilizados de muchos problemas sociales, al grado en que luego son criminalizados y sus derechos humanos, laborales, sociales y políticos suelen ser escamoteados. Cuando bajo el armazón de un bloque económico regional un país subdesarrollado dirige el grueso de su flujo migratorio hacia el país central, no sólo se desarrollan fuertes lazos de dependencia, pues vulnera, entre otras cosas, su soberanía laboral, sino que también se articula un sistema migratorio consolidado. Esto no quiere decir que el país central pase a depender de la fuerza de trabajo barata del país proveedor, puesto que dispone de muchas otras regiones del mundo para recurrir a su abasto. En el caso particular de la integración económica regional de América del Norte, para México su integración con Estados Unidos adquiere un patrón asimétrico y subordinado. Es asimétrico en términos socioeconómicos porque las 
condiciones estructurales entre ambos países son completamente diferentes, mientras Estados Unidos es la primera potencia capitalista del orbe, México es un país subordinado y dependiente de su relación con Estados Unidos. Es subordinada en términos políticos y geoestratégicos dado que México supedita sus designios a las decisiones geoestratégicas de su vecino del norte y renuncia a una agenda política acorde a sus propios intereses.

Los procesos de integración regional no sólo se producen entre norte y sur sino que toman lugar también entre países del norte y entre países del sur con implicaciones diferenciadas. Estos procesos han dado lugar a una cierta reconfiguración de los flujos migratorios al convertir a países de emigración en países que simultáneamente son países de tránsito y de inmigración, así como a la formación de encadenamientos de procesos migratorios sur-norte y sur-sur.

3) Entorno nacional. La política neoliberal de ajuste estructural genera un ciclo depresivo en las economías subdesarrolladas, constriñe el mercado interno, debilita la capacidad de generar empleo formal bien remunerado y alienta el flujo migratorio hacia los países desarrollados, principalmente. El punto nodal es que libera fuerza de trabajo que se configura como una apreciable sobrepoblación, que es una reserva laboral a disposición del proceso de reestructuración productiva. Este proceso se da, por una parte, como un drástico proceso de destrucción de cadenas productivas y relaciones sociales de producción, y, por la otra, como la construcción de nuevos vínculos entre países desarrollados y subdesarrollados, lo cual recrudece las relaciones de dependencia y asigna una fuerte carga a los países subdesarrollados dentro de la estrategia regional y global de reestructuración productiva. Asimismo desmantela la institucionalidad del modelo anterior -desarrollista o de sustitución de importaciones en el caso de América Latina, que originó un cierto Estado de bienestar- para dar cabida a la nueva política social, que no es otra cosa sino la focalización de magros recursos hacia los sectores más vulnerables de la sociedad con el afán de conferirle un «rostro humano» al desastre social ocasionado por la política neoliberal. Si con el llamado Consenso de Washington, enunciado en la décadas de los ochenta, se impulsaban las políticas neoliberales de ajuste estructural, como liberalización comercial y financiera, privatización, entre otras, con el surgimiento en los años recientes del Posconsenso de Washington los organismos internacionales pretenden conferirle una especie de rostro humano al capitalismo neoliberal que han construido al invocar temas como combate a la pobreza, equidad e inclusión social. En la misma sintonía se encuentran las metas de desarrollo del milenio de la Organización de las Naciones Unidas (ONU) sin procurar cambios estructurales e institucionales en la globalidad neoliberal.

4) Niveles intranacionales. En las localidades y regiones intranacionales exportadores de migrantes, y a nivel agregado en los países exportadores de migrantes, se ha desarrollado una dependencia respecto de las remesas para apuntalar el consumo y cubrir la subsistencia familiar y social. Más aún, se pretende que el uso de las remesas en obras públicas, proyectos sociales e inversión productiva detone 
el desarrollo local. En los países exportadores, los migrantes son concebidos institucional y socialmente como un sostén de la precaria estabilidad macroeconómica, política y social, agravada de por sí debido a los influjos de la globalización neoliberal. Por si fuera poco, en el ideario de los organismos internacionales y los gobiernos de los países exportadores, las remesas se conciben como un supuesto recurso estratégico para propiciar el desarrollo, sea a escala nacional, regional o local, sin que esas instancias se comprometan a dotar de recursos adicionales y en cuantía suficiente para detonar verdaderos procesos de desarrollo. En los hechos, las remesas fungen como un suplemento a los raquíticos presupuestos públicos orientados al desarrollo social, como lo postulan los programas de descentralización neoliberal.

En este nivel operan también reconfiguraciones de los espacios socioeconómicos, y asociadas a ello el encadenamiento de migraciones internas e internacionales y nuevos trazos de las rutas migratorias en general.

\section{DIALÉCTICA ENTRE DESARROLLO Y MIGRACIÓN: \\ EL CASO DE LA INTEGRACIÓN REGIONAL MÉXICO-ESTADOS UNIDOS}

Desde finales de la década de los setenta, Estados Unidos impulsa en América Latina las políticas neoliberales de ajuste estructural, las cuales fueron operadas por diversos organismos internacionales en conjunción con las clases dominantes y gobiernos nacionales (Veltmeyer, 2000). Estas disposiciones provocaron el vuelco de las economías hacia la exportación, en consonancia con el impulso de nuevas modalidades de integración regional.

La orientación exportadora de la economía mexicana y la modalidad particular de integración regional en la que se inscribe, signada por el Tratado de Libre Comercio de América del Norte (TLCAN), son resultado de las prácticas estratégicas de determinados agentes comandados, como apuntamos en el inciso anterior, por las grandes corporaciones transnacionales y el gobierno de Estados Unidos, bajo el paraguas de algunos organismos internacionales. En efecto, como ha sido ampliamente documentado en la literatura, en la génesis y puesta en marcha del TLCAN figura un sector de la clase política de Estados Unidos en alianza con las grandes corporaciones transnacionales de ese país y sus contrapartes en Canadá y México (Cypher 1993; Faux 2006). En el caso mexicano, además del gobierno, destaca la activa participación de un sector de la cúpula empresarial mexicana encabezada por el Consejo Coordinador Empresarial y que se agrupa en torno a la Comisión de Organismos Empresariales de Comercio Exterior (Puga 2004; Cypher y Delgado Wise, 2007).

En este contexto, México se convierte, en relativamente corto tiempo, en el principal exportador de Latinoamérica y decimotercero del mundo debido a una supuesta aplicación exitosa de las reformas económicas. A primera vista, su pla- 
taforma de exportación se conforma en un $90 \%$ de productos manufacturados, de los cuales $39.4 \%$ son clasificados como «bienes difusores de progreso tecnológico» (CEPAL, 2002). En virtud de la ilusión óptica que pudiera generar dicho posicionamiento, resulta crucial esclarecer żqué es lo que verdaderamente exporta el país?

\section{El modelo exportador de fuerza de trabajo barata}

Para dar una respuesta certera, conviene señalar que las políticas neoliberales y, particularmente el TLCAN, definen el proceso actual de integración de la economía mexicana a la estadounidense. Este proceso encuentra fundamentación teórica en el concepto de modelo exportador de fuerza de trabajo a través de la operación de tres mecanismos complementarios (Delgado Wise y Márquez, 2005; Delgado Wise y Cypher, 2005):

1. La industria maquiladora, concebida como plantas de ensamble asociadas a procesos productivos internacionalizados, con muy escasa integración a la economía nacional.

2. La maquila encubierta, referida a plantas manufactureras con procesos productivos relativamente más complejos que la maquila, pero que operan bajo el mismo sistema de importación temporal.

La maquila y la maquila encubierta comparten dos características importantes: a) carecen prácticamente de encadenamientos productivos, hacia delante y hacia atrás, con el resto del aparato productivo nacional, y $b$ ) están sometidas a fuertes procesos de precarización laboral con salarios que oscilan, frente a los salarios manufactureros en Estados Unidos, en una relación de 1/10 en la maquila y 1/7 en la maquila encubierta.

3. La migración laboral, denota el creciente éxodo de mexicanos al exterior. Es resultado de la estrechez y precarización del mercado laboral mexicano derivada de la reestructuración neoliberal y opera como reserva laboral y suministro de mano de obra barata altamente precarizada para la economía estadounidense.

Para precisar el contenido de las exportaciones mexicanas resulta fundamental develar el significado de lo que en realidad exporta el país a través de la maquila y la maquila encubierta. Debido al elevado componente importado de ambas actividades, entre 80 y 90\% del valor de las exportaciones, el saldo para México se reduce básicamente a la derrama salarial, esto es, al valor de la fuerza de trabajo incorporado a las exportaciones. Lo cual significa que se trata de una exportación indirecta de fuerza de trabajo o, si se quiere, de exportación de fuerza de trabajo sin que los trabajadores mexicanos salgan del país (Tello, 1996). Este es un elemento conceptual crucial que desmitifica el carácter supuestamente manufacturero de las exportaciones mexicanas, y que da cuenta de una regresión en la plataforma exportadora. Si a la exportación indirecta de fuerza de trabajo se le suma la expor- 
tación directa de fuerza de trabajo vía migración laboral, queda claro el contenido real de las exportaciones mexicanas. De ahí nuestra caracterización del modelo actual de crecimiento exportador como modelo exportador de fuerza de trabajo barata.

\section{La nueva dinámica migratoria}

Bajo este modelo, como se aprecia claramente en la gráfica 1, la migración MéxicoEstados Unidos ha tenido un crecimiento exponencial en el curso de las últimas dos décadas. Este crecimiento se acentúa con la puesta en marcha del TLCAN, posicionando a México como el principal emisor de migrantes a Estados Unidos.

GRÁFICA 1

Población de origen mexicano en Estados Unidos

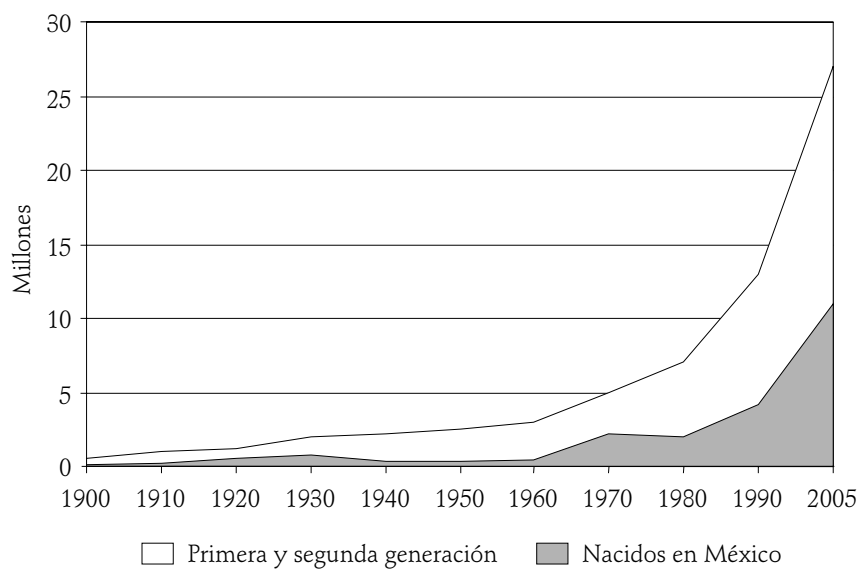

Fuente: Estimaciones de Conapo basadas en el Current Population Survey.

Las dimensiones que alcanza el fenómeno migratorio son por lo demás elocuentes: en 2007 la población de origen mexicano que reside en Estados Unidos se estima en casi 30 millones de personas, entre emigrantes -documentados o nonacidos en México (12 millones) y ciudadanos estadounidenses de ascendencia mexicana. Se trata de la diáspora más grande del mundo establecida en un país. De acuerdo con estimaciones de la onU (2006), para 1990-1995 México figura como el país con el mayor número de personas que anualmente establecen su residencia en el extranjero (400,000, frente a 390,000 de China y 280,000 de India). Entre 2000 y 2005 el éxodo anual de mexicanos fue de 560,000. A tono con esta dinámica, el país experimenta un crecimiento exponencial en la recepción de remesas, y por ello figura como primer receptor del mundo junto con India (IFAD, 2007). En 2006, el monto de las remesas ascendió a 23 mil millones de dólares (Banco de México, 2007). 
Prácticamente todo el territorio mexicano registra incidencia migratoria internacional, puesto que en 2000, 96.2\% de los municipios experimenta algún tipo de relación con esta última. Esta expansión territorial da lugar a la emergencia de nuevos circuitos migratorios (histórico, indígena-tradicional, emergente, etcétera) con dinámicas y problemáticas contrastantes (Zúñiga y Leite 2004). En paralelo, la población residente en Estados Unidos de origen mexicano -no obstante continuar concentrada en un puñado de estados- se ha expandido en los últimos años hacia la mayoría del territorio de ese país. Cabe apuntar, entre otras cosas, que está aconteciendo una expansión de los circuitos migratorios hacia el este y centro-norte de Estados Unidos (Zúñiga y Hernández-León, 2005), precisamente donde se ubican algunos de los centros más dinámicos de la reestructuración industrial (Champlin y Hake, 2006).

En términos de escolaridad, el 38.9\% de la población de 15 años y más, nacida en México y residente en Estados Unidos, cuenta con un nivel educativo superior al bachillerato. Este dato se eleva a $52.4 \%$, al considerar todo el espectro de la población de origen mexicano establecida en aquel país. En contraste, la media para México es de $27.8 \%$, lo que significa que, contra lo que se supone, se está yendo más fuerza de trabajo calificada de la que tiende a quedarse en el país; es decir, hay una clara tendencia selectiva, consustancial a la racionalidad subyacente en las migraciones internacionales. Vale la pena acotar, sin embargo, que comparado con otros grupos de inmigrantes, el contingente mexicano es el de menor escolaridad en Estados Unidos. Esta circunstancia no atenúa este problema sino que evidencia el grave rezago educativo que persiste en México (OCDE, 2005).

Un tipo de desplazamiento menos visible, y que se sale de los estereotipos de la migración laboral, es el correspondiente a los mexicanos residentes en Estados Unidos que cuentan con un nivel de escolaridad equivalente a licenciatura o posgrado. En este caso, el monto asciende a poco más de 385 mil personas nacidas en México. Con posgrado son 86 mil, de los cuales 10 mil cuentan con el grado de doctor (Bureau of Census, 2005). Esto evidencia que la fuga de cerebros comienza a manifestarse como un problema de consideración.

Todos estos cambios han estado acompañados de una transformación en el patrón migratorio: de un patrón con predominio del migrante circular se pasa a uno con preeminencia del migrante establecido, incluidas algunas variantes como la mayor participación de mujeres y familias enteras (Delgado Wise, Márquez y Rodríguez, 2004). Si bien la tendencia al establecimiento suele ser resultado de la evolución y maduración de los flujos migratorios, en este caso se acompaña de la impronta del cierre unilateral de la frontera que, contra sus propósitos enunciativos, en vez de contener el éxodo poblacional propicia que flujos emergentes -ante la dificultad y riesgos del retorno- opten por prolongar su estancia indefinidamente.

El cambio en el patrón migratorio y la disminución de las tasas de natalidad en el país, están dando lugar a una creciente y preocupante tendencia al despobla- 
miento: de 2000 a 2005, 832 de los 2,435 municipios del país (uno de cada tres) registraron una tasa negativa de crecimiento (INEGI, 2006).

Cabe agregar que junto a este fenómeno y en virtud de la prolongación hemisférica de la política de integración económica promovida por el gobierno estadounidense, México fue compelido también a fungir, de manera creciente, como un país de tránsito, con todos los problemas que ello acarrea. Considérese que en 2004 el flujo de indocumentados, principalmente centroamericanos, que transitaron por la frontera sur mexicana fue de poco más de 400 mil personas (INM, 2005).

\section{Paradojas del crecimiento exportador}

Para concluir esta sección, es pertinente destacar que la modalidad de exportación de fuerza de trabajo, que está en la base del sistema migratorio México-Estados Unidos, arroja dos paradojas sintomáticas de la insustentabilidad del esquema actual de integración económica:

- La integración económica auspiciada por el TLCAN en lugar de promover una convergencia en términos del desarrollo entre México y Estados Unidos, contribuye a profundizar las asimetrías entre ambos países. Mientras que en 1994 el PiB per cápita estadounidense representaba 2.6 veces el mexicano, en 2004 la relación se había ampliada a 2.9. Por su parte, el salario manufacturero estadounidense medido en dólares por hora hombre representaba 5.7 veces el mexicano en 1994 y 6.8 en 2004. Paradójicamente, mientras la zanja entre los ingresos salariales percibidos en México y Estados Unidos se abre cada vez más, no ocurre lo mismo con los niveles de productividad, puesto que en ese caso han tendido a acortarse, incluso en ciertos casos la productividad es mayor en México en algunos sectores productivos, particularmente en aquellos que forman parte del modelo exportador de fuerza de trabajo mexicana.

TABLA 1

Asimetrías México-Estados Unidos, 1994-2004

\begin{tabular}{|c|c|c|c|c|}
\hline \multirow[b]{2}{*}{ ASIMETRÍA } & \multicolumn{2}{|c|}{ MÉXICO } & \multicolumn{2}{|c|}{ ESTADOS UNIDOS } \\
\hline & 1994 & 2004 & 1994 & 2004 \\
\hline Población (miles) & 88,402 & 104,000 & 263,126 & 293,655 \\
\hline Tasa de crecimiento poblacional & $3.2^{\mathrm{a}}$ & 1.3 & $1,2^{\mathrm{a}}$ & 1.0 \\
\hline РІв per cápita dólares corrientes & 7,332 & 10,059 & 19,304 & 29,673 \\
\hline Subempleo (\% de la PEA) & 43.7 & 37 & 8.8 & 7.6 \\
\hline Gasto en investigación y desarrollo (\% del PІв) & 0.29 & $0.43^{b}$ & 2.42 & $2.68^{\mathrm{b}}$ \\
\hline $\begin{array}{l}\text { Población con estudios de licenciatura } \\
\text { (\% de población entre } 25 \text { y } 64 \text { años) }\end{array}$ & $11.9^{a}$ & $15.4^{\mathrm{b}}$ & $33.3^{\mathrm{a}}$ & $38.4^{\mathrm{b}}$ \\
\hline Salarios manufactureros (dólares por hora-hombre) & 2.1 & 2.5 & 12 & 16.2 \\
\hline
\end{tabular}

a $1995^{\mathrm{b}} 2003$.

Fuentes: OCDE, INEGI. 
- La integración económica en lugar de generar opciones ocupacionales en México se convierte en un motor de la exportación directa de fuerza de trabajo y acentúa la dependencia socioeconómica de las remesas. Las remesas representan la fuente de divisas que registra el crecimiento más consistente, lo que se hace más visible debido a la pérdida de importancia relativa de otras vías de financiamiento externo, como la inversión extranjera directa (IED) y las exportaciones de la industria maquiladora. Durante el periodo de aplicación de la política neoliberal, según los datos oficiales, la recepción de remesas se multiplicó 30 veces.

Bajo estas consideraciones, es posible sostener que la migración opera, sin proponérselo y sin que sea parte de la agenda de los migrantes, como un soporte crucial del engranaje neoliberal, confiriéndole un cierto cariz de «estabilidad»y, paradójicamente, un «rostro humano». A nivel macro las remesas sirven para prolongar la vida de un modelo de desarrollo que muestra ya signos de insustentabilidad, y a nivel micro fungen como un paliativo de la pobreza y marginación, en tanto implican una transferencia de recursos sin vínculos sólidos con el ahorro, el mejoramiento de la capacidad productiva y el crecimiento económico.

\section{La tentativa de un proyecto de cambio}

Ante la necesidad de promover cambios profundos en las dinámicas estructurales y en las prácticas estratégicas que moldean el actual esquema de integración regional y la política de desarrollo nacional de corte neoliberal, afloran dos configuraciones de agentes sociales que podemos identificar como ubicados «desde arriba»y "desde abajo». El proyecto dominante claramente está orquestado "desde arriba», como lo hemos venido planteando, por los agentes del capital y el poder de Estados Unidos y México al amparo de una coalición política tendiente a mantener y llevar hasta sus últimas consecuencias la integración neoliberal: Se trata de un verdadero proyecto de clase que actúa como motor de las asimetrías económicas, las desigualdades sociales y fenómenos lacerantes como la pobreza, el desempleo, la precarización laboral y la migración.

En contraste, «desde abajo», sobre todo en México, prolifera la inconformidad y el desánimo, pero también manifestaciones francas de oposición, resistencia y rebelión. Es cierto que hoy por hoy no existe un agente colectivo articulador de un proyecto de cambio que afronte el proyecto comandado por las élites neoliberales; sin embargo es digno de tomar en cuenta que se registran, de forma dispersa, incluso voluntarista y también esperanzadora, movimientos sociales alternativos.

En México atestiguamos sectores que impugnan el actual esquema de integración regional, particularmente el TLCAN, como ocurre destacadamente con el sector agrícola, uno de los más afectados en términos productivos, comerciales, poblacionales y ecológicos, es el caso del movimiento El Barzón, El Campo No 
Aguanta Más (Bartra, 2003) y la campaña Sin Maíz no hay País, entre otros; sectores que impugnan desde distintas trincheras y distintos tonos el modelo excluyente de desarrollo neoliberal, como el Ejército Zapatista de Liberación Nacional (EZLN) y la Otra Campaña y algunos sectores de la izquierda social y electoral que convergen en la Coalición por el Bien de Todos y la Convención Nacional Democrática. Además existen otras manifestaciones sociopolíticas de mayor o menor relevancia nacional, sin embargo salta a la vista el hecho de que el descontento, aún pudiendo ser mayoritario entre la población mexicana, no se expresa de manera organizada, ni existe un verdadero proyecto alternativo de desarrollo.

En el plano México-Estados Unidos, el accionar de los actores del cambio es todavía más difuso. En un principio se manifestó en la Red Mexicana de Acción frente al Libre Comercio y su interlocución con organizaciones paralelas de Estados Unidos y Canadá opositores a la firma del TLCAN, después se ha venido manifestando incidentalmente y de manera temática alguna convergencia entre sindicatos y organizaciones sociales de ambos lados de la frontera (Brooks y Fox, 2004).

En el caso del fenómeno migratorio, por más de una década se ha venido promoviendo la idea de que los migrantes son agentes del desarrollo. Esta proposición además de insostenible a nivel de procesos de transformación social de gran calado, sugiere que los migrantes debieran ser los responsables principales de generar procesos de desarrollo en sus países de origen. No obstante, en la sociedad migrante también encontramos la emergencia de actores sociales que actúan, como lo destaca Fox (2005), en tres planos: i) la integración a la sociedad estadounidense: sindicatos, medios de comunicación, organizaciones religiosas, entre otras; ii) la vinculación y promoción del desarrollo de los lugares de origen: organizaciones de oriundos, y iii) relaciones binacionales que combinan los dos tipos anteriores: organizaciones panétnicas. En este renglón podemos destacar, en México, la participación de las organizaciones de migrantes en la realización de obra pública y proyectos sociales en sus lugares de origen al amparo del Programa Tres por Uno y, en Estados Unidos, las multitudinarias movilizaciones de inmigrantes en la primavera de 2006 en pos de la defensa de sus derechos laborales, políticos, sociales y civiles.

En una visión de conjunto, podemos aseverar que los migrantes y sus organizaciones influyen en distintos grados en la vida política, social, económica y cultural de sus lugares de origen, destino o ambos, pero conviene advertir del error teórico de plantear que los migrantes configuran en sí mismos un agente colectivo de transformación. Si lo que interesa es vislumbrar a los migrantes como agentes del desarrollo, más valdría tomar nota de los proyectos estratégicos y las dinámicas estructurales que se despliegan en distintos planos y niveles, y del juego de intereses que nutre la participación de agentes y actores «desde abajo» $y$ «desde arriba» para comprender el papel desempeñado por los migrantes. Sin embargo, la idea de que los migrantes no son agentes del desarrollo no está hermanada con un mensaje de pesimismo e inmovilismo; por el contrario, es el punto de partida para 
dilucidar la posible articulación de los migrantes organizados con sectores sociales comprometidos en la promoción de una agenda de transformación en los planos global, regional, nacional y local. Sólo entonces podremos discutir la configuración de un agente de transformación social con la participación de los migrantes.

\section{REFLEXIONES FINALES}

El enfoque teórico que hemos delineado en este trabajo identifica cuatro aspectos cruciales para analizar críticamente el nexo entre desarrollo y migración:

1. Una visión crítica de la globalización neoliberal. En contraposición al postulado ideológico de la inevitabilidad de la globalización y el neoliberalismo, se plantea la insustentabilidad e ilegitimidad de la fase actual del capitalismo contemporáneo. Esta situación demanda cambios sustanciales en el actual orden mundial.

2. La reconstrucción crítica del campo de estudios del desarrollo. El predominio del pensamiento único, que descansa en la idea de que el libre mercado es el mecanismo que asigna eficientemente los recursos y genera esquemas de convergencia económica entre los países y sus pueblos, ha dado muestras evidentes de su fracaso. Ante la necesidad de postular alternativas teóricas y prácticas, proponemos repensar el desarrollo como proceso de transformación social que implica cuestionar los postulados de la globalización neoliberal, y asumir una visión multidimensional, multiespacial y debidamente contextulizada. Esta comprensión integral del fenómeno, significa recuperar la perspectiva de los países subdesarrollados tomando en cuenta las dimensiones estratégicas y estructurales del fenómeno desglosadas en los ámbitos global, regional, nacional y local.

3. Configuración del agente del desarrollo. El proyecto globalizador comandado por Estados Unidos, cuyos beneficiarios se reducen a una pequeña élite capitalista, ha perdido el consenso ante la desbordante masa de excluidos y damnificados en todo el planeta. Esto ha detonado la necesidad de un cambio drástico en el entramado económico, político, social, cultural y ambiental. No obstante, una agenda de transformación social de tamaña envergadura no puede tener factibilidad si no se conjugan movimientos, clases y agentes diversos que converjan en sus objetivos y luchas. La configuración de un agente transformador requiere no sólo de un proyecto alternativo de desarrollo teórica y empíricamente fundamentado, sino también de abrir el diálogo, compartir experiencias, conciliar intereses y visiones y construir alianzas en el marco de las relaciones sur-sur y sur-norte.

4. Redimensionamiento del campo de estudios en migración y desarrollo. En la actualidad, la explosión de la migración forzada se inscribe en un engranaje amplio y complejo: la globalización neoliberal. Para entender este proceso resulta imprescindible redefinir los linderos del campo de estudios de migración y desarrollo, ampliándolos e invirtiendo los términos de la relación para situar la compleja problemática del desarrollo y subdesarrollo en el centro del análisis. Esta perspectiva implica, a su vez, una forma diferente de explicar y entender la migración internacional, donde los migrantes y sus organizaciones no deben ser considerados como respon- 
sables en la activación de procesos de desarrollo en sus países, regiones y localidades de origen. Pero tampoco se trata de hacer una valoración negativa de los migrantes; por el contrario es importante poner de relieve la contribución directa que hacen al desarrollo de los países receptores y los aportes a sus lugares de origen. Y más aún, resulta impostergable identificar caminos viables hacia nuevos estadios de desarrollo donde la migración adquiera un estatuto voluntario en vez de forzado. La reconstrucción crítica de este campo demanda nuevos enfoques teóricos y metodológicos, que se traduzcan en nuevas agendas de investigación, conceptos, categorías analíticas y sistemas de información. Esto último constituye un incentivo para debatir de manera constructiva y para crear formas de trabajo colectivo en el ámbito de la investigación a través de la conformación de equipos interdisciplinarios, interinstitucionales e internacionales.

Finalmente, podemos agregar que el análisis del proceso de integración regional de México a la órbita del capitalismo estadounidense ilustra la pertinencia de nuestra propuesta teórica, a la vez que destaca la complejidad y multidimensionalidad de la problemática, por encima de los estudios y concepciones dominantes.

\section{REFERENCIAS}

Bambirra, Vania (1978), Teoría de la dependencia: una anticrítico, México, Era.

Banco de México (2007), Informe anual 2006. México: Banco de México.

BanXICO (2006), Remesas familiares, disponible en www.banxico.org.mx, consultado en septiembre de 2006.

BARTRA, Armando (2003), Cosecha de ira: Economía política de la contrarreforma agraria, México, Itaca.

Bello, Walden (2006), «The Capitalist Conjuncture: over-acumulation, financial crises, and the threat from globalisation», Third Word Quarterly, vol. 27, núm. 8.

Brooks, David y Jonathan Fox (2004), "Ten Years of Cross-Border Dialogues», Americas Program, Interhemispheric Resource Center, disponible en www.irc-online.org, consultado en agosto de 2007.

Bureau of Census (2005), Current Population Survey. <http://www.bls.census.gov>

Cardoso, Fernado Henrique y Enzo Faletto (1969), Dependencia y Desarrollo en America Latina, México, Siglo XXI.

CEPAL (2002), Globalización y desarrollo, Santiago, Cepal, ILPES, ONU.

CHAmplin, Dell y Eric Hake (2006), Immigration as Industrial Strategy in American Meatpacking, Review of Political Economy, vol. 18, núm. 1, pp. 49-70.

Cypher, James (1993) «The Ideology of Economic Science in the Selling of NAFTA: The Political Economy of Elite Decision-Making», Review of Radical Political Economics, vol. 25, núm. 4, pp. 146-163.

y Raúl Delgado Wise (2007), «Restructuring Mexico, Realigning Dependency: Harnessing Mexican Labor Power in the NAFTA Era», working paper, Doctorado en Estudios del Desarrollo, Universidad Autónoma de Zacatecas. 
Delgado Wise, Raúl y Humberto Márquez Covarrubias (2005), «Migración, políticas públicas y desarrollo. Reflexiones en torno al caso de México", Seminario Problemas y Desafíos de la Migración y el Desarrollo en América, Red Internacional de Migración y Desarrollo, 7-9 de abril, Cuernavaca, Morelos. y James Cypher, (2005), «The Estrategic role of Labor in Mexico's Subordinated Integration into the US Production System Under NAFTA», Documento de trabajo 12/ 11/2005, Doctorado en Estudios del Desarrollo, Universidad Autónoma de Zacatecas. Humberto Márquez y Héctor Rodríguez (2004), «Organizaciones transnacionales de migrantes y desarrollo regional en Zacatecas», Migraciones internacionales, vol. 2, núm. 4.

Dos Santos, Theotonio (1974), Dependencia y cambio social, Buenos Aires, Amorrortu.

Faux, Jeff (2006), The Global Class War, Hoboken, New Jersey, John Wiley \& Sons.

Fox, Jonathan (2005), «Repensar lo rural ante la globalización, La sociedad civil migrante», Migración y desarrollo, núm. 5, pp. 35-58.

Frank, André Gunder (1974), Capitalismo y subdesarrollo en América Latina. Buenos Aires: Siglo XXI.

FurTado, Celso (1969), Desarrollo y Subdesarrollo, Buenos Aires, Editorial Universitaria. Guarnizo, Luis Eduardo (2003). "The economics of transnational living», International Migration Review, vol. 37, núm. 3, pp. 666-699.

Harvey, David (2007), «Neoliberalism as creative destruction», The Annals of the American Academy of Political and Social Science, núm. 610, pp. 21-44.

IfAD (2007), Sending Money Home. Worwide Remittance Flows to Developing Countries, Roma, International Fund for Agricultural Development.

INEGI (2006), Conteo de población y vivienda, México, INEGI.

InM (2005), Propuesta de política migratoria integral en la frontera sur de México, México, Instituto Nacional de Migración.

Marini, Ruy Mauro (1973), Dialéctica de la dependencia, México, Era.

Márouez Covarrubias, Humberto (2006), «El desarrollo participativo transnacional basado en las organizaciones de migrantes», Problemas del desarrollo, vol. 37, núm. 144, pp. 121-144.

OCDE (2005), «La emigración de mexicanos a Estados Unidos», Comercio exterior, vol. 55, núm. 2, pp. 148-165.

ONU (2006), «Seguimiento de la población mundial, con especial referencia a la migración internacional y el desarrollo", Informe del Secretario General, E/CN.9/2006/3, 25 de enero.

PugA, Cristina (2004), Los empresarios organizados y el Tratado de Libre Comercio de América del Norte, México, D.F., Miguel Ángel Porrúa.

Tello, Carlos (1996), «La economía mexicana: hacia el tercer milenio», Nexos, núm. 223, pp. 47-55.

VeltMeYer, Henry (2000), Latinoamérica: el capital global y las perspectivas de un desarrollo alternativo, Zacatecas, UAZ/UNESCO.

ZúNíiGA, Elena y Paula Leite (2004), «Los procesos contemporáneos de la migración MéxicoEstados Unidos: una perspectiva regional y municipal», ponencia presentada en el Seminario Migración México-Estados Unidos: Implicaciones y retos para ambos países, México, CONAPO.

ZúNígA, Víctor y Rubén Hernández-León (editores) (2005), New Destinations: Mexican Immigration in the United States, Nueva York, Russell Sage Foundation. 
